\title{
EN TORNO AL EFECTO RETROACTIVO DEL DERECHO DE OPCIÓN DEL ACREEDOR, EN EL SISTEMA JURÍDICO ESPAÑOL
}

\author{
AROUND THE RIGHT BACKDATED CREDITOR OPTION \\ IN THE SPANISH LEGAL SYSTEM
}

\author{
JOSÉ MAXIMILIANO RIVERA RESTREPO* \\ Profesor de Derecho Civil \\ Universidad Gabriela Mistral \\ Santiago - Chile
}

\section{RESUMEN}

La presente investigación tiene por finalidad analizar el efecto retroactivo de la resolución de un contrato, en el sistema jurídico español. Sin perjuicio de las notas sobre doctrina y jurisprudencia españolas, también se incluyen algunas observaciones en torno al Derecho italiano.

Palabras clave: Derecho de opción; resolución; retroactividad; incumplimiento contractual; derecho de remedios.

\footnotetext{
* Abogado de la Universidad de Chile, Magíster en Derecho con mención en Derecho Privado, Universidad de Chile. Máster Universitario en Derecho Privado y Doctor en Derecho por la Universidad Complutense de Madrid. Notario Público, Conservador de Bienes Raíces, Comercio, Minas y Archivero Judicial Suplente de Tocopilla. Profesor de Derecho Civil, Universidad Gabriela Mistral. Dirección postal: Ricardo Lyon N 1177, Providencia, Santiago de Chile, Código Postal: 7510549. E-mail: jose. rivera@ugm.cl. Artículo recibido el 10 de noviembre de 2016 y aceptado para su publicación el 5 de enero de 2017.
} 


\title{
ABSTRACT
}

This research aims to analyze the retroactive effect of the termination of a contract, in the Spanish legal system. Without prejudice to the notes on Spanish doctrine and jurisprudence, some observations on Italian Law are also included.

Keywords: Right option; resolution; retroactivity; creditor's claim; law remedies.

\author{
"[A ORfEO, hijo de EAgRo] \\ Apolo le obsequió con una lira, \\ y las musas le enseñaron a utilizarla, \\ de tal modo que no solo hechizaba a las \\ bestias salvajes sino que además lograba \\ que los árboles y las rocas dejaran sus sitios \\ para seguir el sonido de la música [...]". \\ (Graves, La leyenda de Orfeo) ${ }^{1}$
}

\section{PRESENTACIÓN ${ }^{2}$}

A modo de nota previa, debo señalar que la actual doctrina española discute si la resolución contractual tiene una eficacia extintiva ${ }^{3} \mathrm{o}$ transformadora de la relación obligatoria. ${ }^{4}$ A pesar de que el artículo 1124 del Código Civil español se encuentra sito en la sección de las condiciones resolutorias, y ello podría suponer que se trata de un modo liberatorio de obligaciones, ${ }^{5}$ debe ser interpretado conforme a su contenido y no a la

1 Graves, Robert, Los mitos griegos (Trad. de Lucía Graves), Ariel, Barcelona, 1984, 249 pp.

2 Abreviaturas específicas: CCe: Código Civil español; STS: Sentencia del Tribunal Supremo español.

3 En este sentido, Clemente Meoro señala que: "En la medida en que la resolución no sólo extingue las obligaciones recíprocas de las partes - de manera que éstas desaparecen y dejan de producir los efectos que les son propios-, sino que, además, tiende a hacer desaparecer los efectos del contrato ya producidos a través de la restitución de las prestaciones ejecutadas, se señala que la resolución se caracteriza por tener eficacia retroactiva, eficacia ex tunc". Clemente Meoro, Mario E., "La resolución por incumplimiento en la propuesta para la modernización del derecho de obligaciones y contratos (2009) de la sección de derecho civil de la comisión general de codificación española”, Boletín del Ministerio de Justicia, 2011 (mayo), Año LXV, No 2131, disponible en http://www.mjusticia.es/ (consultado al 9 de marzo de 2014), pp. 9-10.

4 En Venezuela, Melich Orsini se refiere a los efectos principales de la resolución judicial: (a) Un efecto liberatorio y (b) una eficacia recuperatoria. Melich OrsinI, José, La resolución del contrato por incumplimiento, Editorial Temis, Caracas, 1982, pp. 306 y ss.

5 En este sentido, Díez-Picazo y Ponce de León señala que: “El primer efecto que produce la resolución 
ubicación del mismo. ${ }^{6}$ Los autores modernos señalan que, en este caso, se debe distinguir entre la extinción de la prestación primaria (en cuya virtud las partes se deben realizar las prestaciones recíprocas) y la relación jurídica. ${ }^{7}$ Ésta no se extingue, sino que se transforma en dos nuevas obligaciones: ejecutar las prestaciones recíprocas e indemnizar daños y perjuicios. ${ }^{8}$ La doctrina ha señalado que el momento en que se perfecciona la resolución contractual es el instante en que el contratante cumplidor hace valer su facultad, sea judicial o extrajudicialmente, ${ }^{9} \mathrm{y}$ con prescindencia de la situación en que se le otorga un plazo al deudor, pero los efectos de la misma operan, como se vio, y por regla general, con efectos retroactivos. ${ }^{10}$ Con todo, el momento preciso en que se perfecciona la resolución, sea judicial o extrajudicialmente, es el instante en que se demanda o notifica la misma, aun en el caso que el juez le conceda un plazo al contratante incumplidor para que cumpla su deber. ${ }^{11}$

El derecho de opción se ejercita por medio de una declaración recepticia

es desvincular a las partes de la relación obligatoria en la que se encontraban inmersas". DíEz-PiCAzo Y Ponce de León, Luis, Fundamentos del Derecho civil patrimonial, Editorial Aranzadi, Navarra, 2008, Vol. II, 'Las relaciones obligatorias', 6a Edición, p. 871.

6 Cfr. Rodríguez-Rosado, Bruno, Resolución y sinalagma contractual, Marcial Pons, Ediciones Jurídicas y Sociales, Málaga, 2013, pp. 153-154.

7 En este sentido, Clemente Meoro señala que: “[...] Esto es lo que dispone el art. 1202.1 PMDOC: «La resolución libera a ambas partes de las obligaciones contraídas en virtud del contrato, pero no afecta a las estipulaciones relativas a la decisión de controversias, ni a cualquiera otra que regule los derechos y obligaciones de las partes tras la resolución». Y esto mismo es lo que establecen los artículos 81.1 CV, 7.3.5 Principios UNIDROIT y 9:305 (2) PECL. De otro lado, no siempre tiene la resolución carácter retroactivo, pues se afirma la irretroactividad de la resolución en una serie de supuestos: a) En primer lugar, cuando no hay restitución por no haber realizado ninguna de las partes la prestación puesta a su cargo o por haberse resuelto un contrato preparatorio de otro contrato. b) En segundo lugar, tampoco tendrá carácter retroactivo la resolución de los contratos de tracto sucesivo cuando ambas partes han estado ejecutando, durante un tiempo, sus respectivas prestaciones. La resolución, en este caso, no afecta a aquellas prestaciones ya ejecutadas por ambas partes, sino que sólo tiene efectos ex nunc, esto es, libera a las partes de cumplir las obligaciones futuras. Esto es lo que establece el art. 1204 PMDOC cuando dispone que «en la resolución de los contratos de ejecución continuada o sucesiva, la obligación de restituir no alcanza a las prestaciones realizadas cuando entre prestaciones y contraprestaciones exista la correspondiente reciprocidad de intereses conforme al contrato en su conjunto»". Clemente Meoro, cit. (n. 3), p. 10.

8 Cfr. Rodríguez-Rosado, cit. (n. 6), pp. 147-148.

9 Cfr. O’Callaghan Muñoz, Xavier, Compendio de Derecho civil, Ediciones Jurídicas DiJUSA, S. L., Madrid, 2008, Tomo II, 'Derecho de obligaciones', 5ª ed. corregida y puesta al día, p. 78; PUIG Brutau, José, Fundamentos de Derecho civil, Bosch, Barcelona, 1988, T. I, Vol. II, $4^{\mathrm{a}}$ ed. revisada, 'Derecho General de las Obligaciones', pp. 132-133.

${ }^{10}$ Cfr. Lacruz Berdejo, José; Sancho Rebullida, Francisco de A.; Luna Serrano, Agustín; Delgado Echeverría, Jesús; Rivero Hernández, Francisco; Rams Albesa, Joaquín, Elementos de Derecho Civil II. Derecho de Obligaciones, Dykinson, Madrid, 2011, Vol. 1º 'Parte General, Teoría General del Contrato', 5 a ed., p. 200.

${ }^{11}$ Cfr. Lacruz B.; Sancho R.; Luna S.; Delgado E.; Rivero H.; Rams A., cit. (n. 10), p. 200. 
del contratante cumplidor, ${ }^{12}$ dirigida a su contraparte. Ésta tiene por finalidad transformar el negocio, extinguiendo la prestación originaria. ${ }^{13}$ En este punto, se debe señalar que hay algunos autores que consideran que lo que se extingue es el contrato. ${ }^{14}$ Así, Carrasco Perera señala que la resolución contractual deja sin efecto el contrato pero no las obligaciones recíprocas. ${ }^{15}$ En este mismo sentido, Díez-Picazo y Ponce de León ha planteado que la resolución contractual pone término a la relación obligatoria (efecto liberatorio). ${ }^{16}$ Estimo que esta opinión es contradictoria, pues, si desaparece el contrato, desde el punto de vista civil no puede mantenerse la relación obligatoria (por falta de causa eficiente).

En cuanto a los efectos de la resolución unilateral, se debe distinguir dos hipótesis: (a) aquellos efectos que surgen de la relación contractual y (b) aquellos efectos indemnizatorios. Los primeros suponen, al parecer, la extinción de la relación jurídica y del contrato, salvo que se trate de una resolución unilateral arbitraria o abusiva, contraria a los postulados de la buena fe y equidad. El contratante en contra del cual va dirigida la resolución puede, según la jurisprudencia, solicitar una indemnización de daños y perjuicios. ${ }^{17}$ Así, la STS de 25 de octubre de 1985 se pronuncia a favor de la concesión de una compensación (no indemnización), por razones de equidad y para impedir un enriquecimiento sin causa (otras sentencias que han reconocido este derecho son: STS de 6 de marzo de 1978, STS de 11 de febrero de 1984, STS de 19 de diciembre de 1985, STS de 30 de junio de 1987 y la STS de 22 de marzo de 1988). Esta “compensación" puede deberse a tres motivos: (i) cuando el acreedor

\footnotetext{
${ }^{12} \mathrm{Al}$ respecto, v. Badia SALILlas, Ángel, "En torno al artículo 1.504 del Código Civil: Requerimiento, resolución y transmisión del derecho del vendedor", en AA.VV., Estudios jurídicos en homenaje a Tirso Carretero, Publicaciones del Cincuentenario del Ilustre Colegio Nacional de Registradores de la Propiedad y Mercantiles de España, Centro de Estudios Hipotecarios, Madrid, 1985, pp. 50 y ss.

${ }^{13}$ Cfr. Rodríguez-Rosado, cit. (n. 6), p. 161.

${ }^{14}$ Cfr. Dell'Aquila, Enrico, La resolución del contrato bilateral por incumplimiento, Ediciones Universidad de Salamanca, Salamanca, 1981, Prólogo de José Luis de los Mozos, p. 196.

${ }^{15}$ Cfr. Carrasco Perera, Ángel, Derecho de los contratos, Editorial Aranzadi, Navarra, 2010, p. 1160.

${ }^{16}$ Cfr. Díez-Picazo y Ponce de León, cit. (n. 5), p. 871.

${ }^{17}$ Cfr. Puig i Ferriol, Lluís.; Gete-Alonso y Calera, María del C.; Gil Rodríguez, Jacinto y Hualde SÁnchez, José J., Manual de Derecho civil, Marcial Pons, Ediciones Jurídicas y Sociales, Barcelona, 2000, T. II, 'Derecho de obligaciones, responsabilidad civil y teoría general del contrato', $3^{\mathrm{a}}$ ed., p. 144.
} 
incurre en una resolución unilateral abusiva, ${ }^{18}$ contraria a la buena $\mathrm{fe}^{19} \mathrm{o}$ que no se funde en una justa causa; ${ }^{20}$ (ii) cuando, a consecuencia de la extinción de la relación jurídica, la parte solicitante experimenta un enriquecimiento que pueda ser calificado de "injusto"; ${ }^{21}$ (iii) por último, es dable también solicitar una indemnización de daños y perjuicios, cuando, frente al incumplimiento

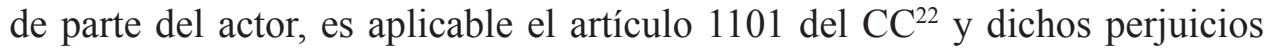
derivan de una situación ajena al desistimiento o resolución unilateral, pues la jurisprudencia no exige que quien solicita el desistimiento haya efectivamente cumplido con sus obligaciones. ${ }^{23}$

\section{DEL EFECTO RETROACTIVO DEL DERECHO DE OPCIÓN}

Cuando las prestaciones recíprocas han sido dadas o ejecutadas, cada parte debe efectuar la repetición de ellas. ${ }^{24}$ Antes de referirme a dicha restitución, debo analizar previamente un aspecto de relevancia, cual es determinar si la resolución contractual tiene o no efecto retroactivo. ${ }^{25}$ Es decir, si produce sus efectos ad initio como en Alemania, o bien, si únicamente tiene efectos para el futuro (Gran Bretaña). En España, es claro para la doctrina y la jurisprudencia,

\footnotetext{
${ }^{18}$ En este sentido se han pronunciado las STS de 11 de febrero 1984, STS de 19 de diciembre de 1985 , STS de 30 de junio de 1987, STS de 22 de marzo de 1988, STS de 16 de septiembre de 1988, STS de 21 de diciembre de 1992, STS de 24 de febrero de 1993 y STS de 17 de octubre de 1995. Cfr. EsPIAU EsPiau, Santiago: La resolución unilateral del contrato: estudio jurisprudencial, Editorial Aranzadi, Pamplona, 1998. Aranzadi Civil-Mercantil, vol. I (Estudio), disponible en http://www.westlaw.es/, 3 de febrero de 2015, p. 13.

${ }_{19}$ Al respecto, v.: STS de 12 de septiembre de 2014 (RJ/2014/466); STS de 19 de febrero de 2014 (RJ/2014/92); STS de 15 de noviembre de 2010 (RJ/2010/713); STS de 9 de julio de 2008 (RJ/2008/652); STS de 23 de junio de 2005 (RJ/2005/503); STS de 17 de abril de 2006 (RJ/2006/411); STS de 12 de julio de 2001, Nº Recurso 1804/1996.

${ }^{20}$ En este sentido, se han pronunciado las STS de 16 de febrero de 1990, STS de 15 de octubre de 1992, STS de 3 de diciembre de 1992, STS de 16 de octubre de 1995 y STS de 18 de diciembre de 1995. Cfr. Espiau Espiau, cit. (n. 18), p. 13.

${ }^{21}$ Ídem, pp. 11-12.

${ }^{22}$ El artículo 1101 del CC español dispone que: "Quedan sujetos a la indemnización de daños y perjuicios causados los que en el cumplimiento de sus obligaciones incurrieren en dolo, negligencia o morosidad, y los que de cualquier modo contravinieren al tenor de aquéllas".

${ }^{23}$ En este sentido se ha pronunciado la jurisprudencia: STS de 11 febrero de 1984 y STS de 22 marzo 1988. Cfr. Espiau Espiau, cit. (n. 18), p. 14.

${ }^{24}$ Al respecto, Díez-Picazo y Ponce de León, cit. (n. 5), p. 872.

${ }^{25}$ En Argentina, Miquel, siguiendo a Halperin, señala que: "[1]a resolución tiene efecto retroactivo quitando toda eficacia al vínculo nacido del contrato [...]". Miquel, Juan L., Resolución de los contratos por incumplimiento, Ediciones Depalma, Buenos Aires, 1986, 2ª Ed. actualizada, p. 231.
} 
que la resolución contractual ${ }^{26}$ opera con efecto retroactivo, ${ }^{27}$ dando lugar al régimen de las prestaciones mutuas. ${ }^{28}$ En este punto, Lacruz Berdejo señala que "[1]a resolución tiene efectos retroactivos es doctrina común, tanto científica como jurisprudencial [...]". ${ }^{29}$ Para Díez-Picazo y Ponce de León: “La doctrina tradicional ha entendido que la resolución se produce con efectos retroactivos y alcanza, por consiguiente, a los negocios que pudiera haber realizado el demandado frente a quien la resolución se pronuncia". ${ }^{30}$ Así, para Navarro Mendizábal: "La resolución tendrá efecto retroactivo siendo el momento de comparación el inmediatamente anterior a la celebración de contrato, teniendo en cuenta que los terceros de buena $\mathrm{fe}^{31}$ quedan a salvo de la retroacción". ${ }^{32}$ Conforme al efecto retroactivo de la resolución, ${ }^{33}$ se deben dejar sin efecto los actos que hubiere ejecutado el demandado. ${ }^{34}$ Aquí se aplica el principio "resoluto

${ }^{26}$ En este sentido, AlBALADEJo GARCÍA señala que: "Se remonta así a la fecha y a la fuente de que nacieron las obligaciones recíprocas, que han de quedar como si no se hubiesen contraído, con devolución de lo recibido por cada parte de la otra [...]". Albaladejo García, Manuel, Derecho Civil. II. Derecho de Obligaciones, Edisofer, S. L., Madrid, 2011, 14ª edición, p. 123.

${ }^{27}$ En este sentido, Lacruz Berdejo; Sancho Rebullida; Luna Serrano; Delgado Echeverría; Rivero Hernández y Rams Albesa señalan lo siguiente: "Que la resolución tiene efectos retroactivos es doctrina común, tanto científica como jurisprudencial (sin perjuicio de discutir luego el alcance de esta retroactividad, en particular para el cálculo de la indemnización)". LACRUZ B.; SANCHO R.; LuNA S.; Delgado E.; Rivero H. y Rams A., cit. (n. 10), p. 200.

${ }^{28}$ Cfr. Bercovitz Rodríguez-Cano, Rodrigo (Director), Comentarios al Código Civil, Tirant lo Blanch, Valencia, 2013, T. VI, arts. 1043 a 1264, pp. 8249-8251; RodRíGUEZ-RosAdo, cit. (n. 6), pp. 161-162.

${ }^{29}$ Cfr. Lacruz Berdejo; Sancho Rebullida; Luna Serrano; Delgado Echeverría; Rivero Hernández y Rams Albesa: Elementos de Derecho Civil. II. Derecho de obligaciones, Dykinson, Madrid, 2007, Vol. $1^{\circ}$, Parte General. Teoría General del Contrato, $4^{\mathrm{a}}$ ed. revisada y puesta al día por Francisco Rivero Hernández, p. 200.

${ }^{30}$ Díez-Picazo y Ponce de León, cit. (n. 5), p. 872. Cfr. Ruiz Serramalera, Ricardo, Derecho civil. Derecho de obligaciones II. Los contratos y los actos ilícitos, Secc. de Publicaciones, Universidad Complutense de Madrid, Facultad de Derecho, Madrid, 1982, p. 106.

${ }^{31}$ Con relación a los efectos de la resolución respecto de terceros, vid.: Clemente Meoro, Mario E., La facultad de resolver los contratos por incumplimiento, Tirant lo Blanch, Valencia, 1998, pp. 547 y ss.; Fernández Urzainqui, Francisco J.; Xiol Ríos, Juan A. (Directores), Código Civil, Grupo El Derecho y Quantor, S. L., Madrid, 2010, pp. 1036-1037.

${ }^{32}$ Navarro MendizÁBal, Iñigo A., Derecho de obligaciones y contratos, Ed. Aranzadi, Navarra, 2011, p. 167.

${ }^{33}$ En este sentido, Puig i Ferriol, Gete-Alonso y Calera, Gil Rodríguez y Hualde Sánchez señalan que: "En el sistema de nuestro Código, que regula la facultad resolutoria a seguido de la disciplina de la retroactividad asociada al cumplimiento de las condiciones y con expresa reserva de los derechos adquiridos por terceros (art. 1.124.IV), parece evidente que la resolución del art. 1.124 no sólo extingue las obligaciones recíprocas desde que aquélla tiene lugar (eficacia ex nunc), sino que, aun tratándose de una ineficacia contractual sobrevenida y no originaria, tiene virtualidad retroactiva (ex tunc): lleva consigo la devolución mutua del precio y de la cosa objeto del contrato". Puig i Ferriol, Gete-Alonso y Calera, Gil Rodríguez y Hualde Sánchez, cit. (n. 17), p. 146.

${ }^{34}$ Al respecto, v. Puig Brutau, cit. (n. 8), p. 135-136. 
iure dantis, resolvitur ius concessum". ${ }^{35}$ La jurisprudencia ha dicho en forma reiterada, que la resolución se produce con efecto retroactivo, ${ }^{36} v . g r$. , la STS de 10 de octubre de $1998 .{ }^{37}$ La STS de 31 de mayo de 1985 (RJ/1985/2837), dispone que: "La resolución del contrato sinalagmático por incumplimiento tiende a cancelar desde un principio los efectos de lo convenido, colocando a los intervinientes en la misma situación en que se encontrarían si el pacto no se hubiese celebrado, efecto que opera ex tunc y que lleva consigo la obligación de restituir a cada parte lo que haya recibido de la otra por razón del vínculo obligacional, ${ }^{38}$ lo que significa que la relación se extingue como si nunca hubiese tenido existencia, sin perjuicio, claro es, del respeto a los derechos de terceros adquirentes de buena fe, tesis mantenida asimismo por esta Sala en las sentencias citadas en el recurso y también en las de 14 de noviembre de 1962 (R.J.A. 4.289), 21 de noviembre de 1963 [R.J.A. (1964) 347], 14 de marzo de 1964 (R.J.A. 1.594) y 16 de octubre de 1967 (R.J.A. 3.823), a cuyo tenor la resolución del contrato supone la extinción de la relación contraída no sólo para el futuro, sino con carácter retroactivo, con la consecuencia de reintegrarse cada contratante de sus prestaciones por razón del negocio, cual sucede en los casos de nulidad y rescisión y en la condición resolutoria expresa del artículo 1.123 del Código Civil". ${ }^{39}$ Por su parte, la STS de 14 de julio de 2008 (RJ/2008/707), dispone que: “[...] Sentado lo anterior, ha de ser rechazado el primer motivo que se refiere a la infracción del artículo 647.2 en relación con el 1124 del Código Civil, ya que la revocación de la donación por dejar de cumplir el donatario la condición o carga impuesta únicamente puede operar sobre una donación con eficacia actual, lo que no ocurre en el caso enjuiciado. Efectivamente en el momento en que se otorgó la donación, la donante impuso una carga a la entidad donataria en orden al destino que había de darse al inmueble donado, pero también estableció una condición resolutoria que,

\footnotetext{
${ }^{35}$ Cfr. Díez-Picazo y Ponce de León, cit. (n. 4), p. 872.

${ }^{36}$ Cfr. Murillo González, Fernando; Echeverría Summers, Francisco; Erdozain López, José C. (Coords.), Código Civil, concordado y comentado. Con jurisprudencia y doctrina de las audiencias provinciales. Ed. Tecnos (Grupo Anaya S.A.), Madrid, 2005, p. 879.

${ }^{37}$ Cfr. Méndez Tomás, Rosa M.; Vilalta Nicuesa, A. Esther, La resolución contractual. Acción resolutoria en el contrato de compraventa, Ed. Bosch, Barcelona, 2002, 2ª ed., p. 15.

${ }^{38}$ Así, la STS de 6 de noviembre de 2009, dispone que: "En principio y regla general, los efectos de la resolución contractual se producen «ex tunc», colocando a los intervinientes en la misma situación en que se hallarían si el contrato no se hubiese celebrado, lo que lleva consigo la obligación de restituir cada parte lo que haya percibido de la otra por razón del vínculo obligacional, sin perjuicio del derecho de terceros adquirentes de buena fe". Cfr. Martorell Zulueta, Purificación (Coord.), Código Civil, Jurisprudencia sistematizada, Editorial Tirant lo Blanch, Valencia, 2011, p. 1280.

${ }^{39}$ Cfr. Clemente Meoro, cit. (n. 31), p. 496.
} 
una vez cumplida, ${ }^{40}$ determinó la extinción del negocio con efectos «ex tunc» (sentencias de 27 febrero 1993 y 21 junio 2002) (1) $^{4}$ la inoperancia de cualquier acción revocatoria posterior". ${ }^{42}$ La STS de 5 de julio de 1980 (RA/1980/5846), dispone que: "[...] constituye efecto fundamental de la resolución extinguir retroactivamente las obligaciones recíprocas, con desaparición de la eficacia del contrato y el retorno a la situación existente antes de su celebración [...]". ${ }^{43}$

En este caso, se deben tener presentes dos disposiciones del CC: los artículos 1295 y 1298. La primera norma dispone, en su apartado $2^{\circ}$ que: "Tampoco tendrá lugar la rescisión cuando las cosas se hallaren legalmente en poder de terceras personas que no hubiesen procedido de mala fe". ${ }^{44}$ El artículo 1298 establece que: "El que hubiese adquirido de mala fe las cosas enajenadas en fraude de acreedores, deberá indemnizar a éstos de los daños y perjuicios que la enajenación les hubiese ocasionado, siempre que por cualquier causa le fuere imposible devolverlas". ${ }^{45}$

El fundamento de la retroactividad, en este caso, se sustenta en que, verificada la resolución de la obligación, no es posible que uno de los contratantes se beneficie con las cosas dadas en virtud de ese negocio, pues ello significaría un enriquecimiento sin causa. Por ello se justifica el retorno a la situación en que se encontraba cada parte al tiempo de celebrar el contrato. ${ }^{46}$ Para Clemente Meoro, "[1] a retroactividad es lo más acorde con el sistema general del Código, en que la restitución no constituye un puro deber jurídico liquidatorio, sino que produce efectos recuperatorios en virtud de la sentencia o de la decisión de resolver"'. ${ }^{47}$

Hay que señalar que la retroactividad de la resolución se aplica únicamente a los contratos con efectos inmediatos, ya que, como se ha esbozado, en los

\footnotetext{
${ }^{40} \mathrm{Al}$ respecto, v. STS de 9 de mayo de 2013 (RJ/2013/241).

${ }^{41}$ También se refieren al efecto retroactivo de la resolución contractual por incumplimiento: STS de 20 de mayo de 2013 (RJ/2013/318); STS de 29 de febrero de 2012 (RJ/2012/99); Auto del TS de 22 de junio de 2010, No Recurso 265/2009; STS de 28 de febrero de 2002 (RJ/2002/164) y STS de 20 de diciembre de $2001(\mathrm{RJ} / 2001 / 1196)$.

${ }^{42}$ STS de 14 de julio de 2008 (RJ/2008/707).

${ }^{43}$ Cfr. Montés Penadés, Vicente L., “Artículo 1.124”, en Albaladejo G., Manuel (Director), Comentarios al Código Civil y Compilaciones Forales, Editorial Revista de Derecho Privado, Madrid, 1989, T. XV, Vol. 1, artículos 1.088 a 1.124 del Código Civil, p. 1157.

${ }^{44}$ Cfr. Dell'Aquila, cit. (n. 14), pp. 176-177.

${ }^{45}$ V. O’Callaghan Muñoz, Xavier, Código Civil. Comentado y con jurisprudencia, Editorial La Ley - Actualidad, Madrid, 2001, $2^{\mathrm{a}}$ ed., pp. 1313-1314.

${ }^{46}$ Cfr. De Cossio y Corral, Alfonso, Instituciones de Derecho Civil, Editorial Civitas, Madrid, 1987, T. I, Parte General. Obligaciones y contratos, p. 297.

${ }^{47}$ Clemente Meoro, cit. (n. 31), p. 502.
} 
contratos de ejecución sucesiva se habla de terminación, precisamente para diferenciarla de la resolución en la primera clase de contratos, por cuanto en los contratos de ejecución sucesiva no se produce el efecto retroactivo. ${ }^{48}$ Lo anterior se justifica, porque, en una obligación de tracto sucesivo, como es el caso del contrato de arrendamiento y el contrato de sociedad, las obligaciones que nacen cada cierto tiempo se extinguen de manera permanente, sin posibilidad de ser restituidas en el devenir. ${ }^{49}$ La liquidación que se realice entre las partes, no atenta contra el carácter permanente de la extinción, ya que su exclusiva finalidad es dejar a los contratantes en la misma situación en que se encontraban al momento de constituirse la relación jurídica. ${ }^{50}$ Dicho de otra manera, las prestaciones que surgen de los contratos de ejecución sucesiva pueden separarse tanto económica como jurídicamente, debido a que cada prestación periódica y recíproca puede ejecutarse parcialmente, satisfaciendo el interés de cada contratante y la finalidad del negocio. Clemente Meoro señala que en este caso existe una "resolución parcial", pretendiéndose con ella evitar un enriquecimiento sin causa, situación que no se da en los contratos de tracto sucesivo. ${ }^{51}$

\section{DE LAS RESTITUCIONES MUTUAS}

Aclarado el efecto retroactivo de la resolución contractual, se debe indicar que los contratantes deben ejecutarse las restituciones recíprocas, ${ }^{52}$ dentro de las cuales se debe devolver los frutos. ${ }^{53}$ Así lo dispone el artículo

\footnotetext{
${ }^{48}$ Cfr. Díez-Picazo y Ponce de León, cit. (n. 5), p. 873.

${ }^{49}$ V. Martorell Zulueta, cit. (n. 38), p. 1280.

${ }^{50}$ Cfr. Larenz, Karl, Derecho civil. Parte general, Editorial Revista de Derecho Privado, Madrid, 1978, p. 693.

${ }^{51}$ Cfr. Clemente Meoro, cit. (n. 31), pp. 503 y 504.

${ }^{52}$ En este sentido, Clemente Meoro plantea lo siguiente: “[...] En el Derecho vigente cabe pensar en dar respuesta a esta cuestión acudiendo a las reglas sobre liquidación del estado posesorio (artículos 451 y ss. CC), o a la aplicación analógica de otras normas previstas para supuestos de pérdida del título del accipiens, como el art. 1120.1 (cumplimiento de la condición cuando la obligación imponga recíprocas prestaciones a los interesados), 1295 (rescisión), $1478.2^{\circ}$ (saneamiento por evicción), 1519 (retracto convencional) y 651.1 (revocación de donaciones). Y también cabe recurrir a la aplicación literal del art. $1123 \mathrm{CC}$, que establece que los interesados «deberán restituirse lo que hubiesen percibido», de donde resulta que sólo han de restituir el bien-madre, sino también los frutos e intereses percibidos; e incluso los que hubiera podido percibir ( $c f r$. artículos 455 y 1896.1 CC), pues el solvens no ha de soportar el coste de la eventual inactividad injustificada del accipiens". Clemente Meoro, cit. (n. 3), pp. 10-11.

${ }^{53}$ En este sentido, Carrasco Perera señala que: "La regulación de la mecánica restitutoria relativa a las prestaciones recibidas se encuentra por remisión parcial en el art. 1295 CC y por analogía -también parcial, como veremos- en el régimen de las nulidades contractuales [...]". CARRASCO PERERA, cit. (n. 15), p. 1149.
} 
1295 del CC: "La rescisión obliga a la devolución de las cosas que fueron objeto del contrato con sus frutos, y del precio con sus intereses". ${ }^{54}$ Esta norma, a pesar de que se refiere a la rescisión, igualmente se aplica a la resolución contractual. ${ }^{55}$ Ésta es la solución adoptada también por la jurisprudencia italiana. (Sentencia de Casación de 6 de octubre de 1970 ( $\left.n^{\circ} 1803\right)$, Sentencia de Casación de 15 de marzo de 1972 ( $n^{0}$ 756), Sentencia de Casación de 13 de enero de 1972 ( $\left.{ }^{\circ} 106\right)$, Sentencia de Casación de 23 de julio de 1964 ( ${ }^{\circ}$ 1986)). ${ }^{56}$ En Francia, al parecer, en la doctrina prevalece la opinión contraria. ${ }^{57}$ Lo anterior se justifica, porque a la eficacia liberatoria de la resolución, la acompaña una eficacia restitutoria, ya que producida la resolución, las partes deben proceder a restituirse todo aquello que hubieren recibido en virtud del contrato. Clemente Meoro menciona, en este sentido, la STS de 5 de mayo de 1980 (RJ/1980/1784), STS de 20 de junio de 1980 (RJ/1980/2412) y STS de 10 de marzo de $1950(\mathrm{RJ} / 1950 / 704){ }^{58}$ Carrasco Perera plantea que no cabe aplicar los artículos 1295 y 1303 del CC por analogía, no procede la repetición de frutos ni intereses, los que únicamente se pueden exigir como resarcimiento por daños y perjuicios generados por el incumplimiento. ${ }^{59}$ En cuanto a las excepciones a la retroactividad, se pueden señalar las siguientes: (i) Como ya se dijo, en los contratos de tracto sucesivo, no opera la retroactividad. Igual situación ocurre en los sistemas jurídicos italiano ${ }^{60}$ y francés $;{ }^{61}$ (ii) en general, la doctrina plantea que la retroactividad no afecta los efectos reales que generan ciertos contratos; ${ }^{62}$ (iii) tampoco se ven afectados los derechos de terceros que

\footnotetext{
${ }^{54}$ En este punto caben dos alternativas: aplicar o no por analogía el artículo 1295 CC que se refiere a los efectos de la nulidad. Cfr. CARrasco Perera, cit. (n. 15), pp. 1155 y ss.

${ }^{55}$ En este sentido, Clemente Meoro señala que: "Se trata de un efecto retrospectivo de la resolución: si ambas o alguna de las partes ha ejecutado su prestación, pueden reclamar su restitución. Pero si la resolución es parcial, la restitución también será parcial”. Clemente Meoro, cit. (n. 31), p. 489.

${ }^{56}$ Cfr. Dell'Aquila, cit. (n. 14), p. 197.

57 Ídem.

${ }^{58}$ Cfr. Clemente Meoro, cit. (n. 31), pp. 474-475.

${ }^{59}$ Cfr. Carrasco Perera, cit. (n. 15), p. 1155.

${ }^{60}$ El artículo 1458 del Codice Civile dispone que: "La resolución del contrato por incumplimiento tiene efecto retroactivo entre las partes, salvo el caso de contratos de ejecución continuada o periódica, respecto a los cuales el efecto de la resolución no se extiende a las prestaciones ya ejecutadas". Cfr. Dell'Aquila, cit. (n. 14), pp. 198-199.

${ }^{61}$ Cfr. Dell'Aquila, cit. (n. 14), p. 198.

${ }^{62}$ En este sentido, Melich Orsini señala que: "[...] la doctrina tradicional, que se pronuncia en favor de la retroactividad real en aquellos casos en que se trata de la resolución de un contrato con eficacia real, no ha dejado de admitir algunas excepciones a dicho principio como concesión a la necesidad de proteger la confianza de los terceros en las situaciones aparentes creadas por las propias partes intervinientes en el contrato". Melich Orsini, cit. (n. 4), p. 313. Montés Penadés la llama, asimismo,
} 
se encuentren de buena fe. ${ }^{63}$ Tratándose de la segunda excepción, y dada las características del sistema español (consagrado en los artículos 609 y 1095 del CC) en el cual la compraventa sólo genera efectos personales, a diferencia de los modelos francés e italiano, ${ }^{64}$ en los cuales el contrato de compraventa genera efectos reales, ${ }^{65}$ se requiere de una efectiva tradición de la cosa para que pueda operar la excepción. ${ }^{66}$ En cuanto a la tercera excepción, solamente el tercero que se encuentre de mala $\mathrm{fe}^{67}$ tendrá que repetir la cosa al contratante leal que haya solicitado y obtenido la resolución de la obligación. ${ }^{68}$

Respecto de los frutos que se hubieran producido en el tiempo intermedio, éstos deberán ser restituidos, y en el caso que se hubieran consumido, se deberá pagar una indemnización por el valor de los mismos. Asimismo, como pena accesoria a la restitución de la cosa principal y los frutos, el contratante cumplidor podrá exigir una indemnización de daños y perjuicios, ${ }^{69}$ conforme a lo dispuesto en el artículo 1124 del CC. Así también lo ha reconocido la jurisprudencia, $v$. gr., la STS de 19 de octubre de $1995 .{ }^{70} \mathrm{El}$ tema de los frutos e intereses que se deben restituir producto de la resolución contractual se encuentra en el artículo 1123 del CC. Esta norma dispone que deberán restituir todo aquello que hubiesen percibido, de tal manera que se

\footnotetext{
"retroactividad real". Cfr. Montés Penadés, cit. (n. 43), p. 1164.

${ }^{63}$ Dell'Aquila, cit. (n. 14), p. 200; O’Callaghan Muñoz, cit. (n. 9), p. 78.

${ }^{64}$ Sobre este punto, Melich Orsini postula lo siguiente: "Al contrario, la tesis de la retroactividad real de la resolución parece consustancial a la estructura de aquellos sistemas de raigambre francesa, como el nuestro y el del derogado Código Civil italiano, donde no se distingue en los contratos que tienen por objeto la trasmisión de la propiedad o de un derecho real sobre un cuerpo cierto, entre el acto obligatorio y causal y el efecto real consecuente, sino que ambos se presentan indisolublemente fusionados". Melich Orsini, cit. (n. 4), p. 317.

${ }^{65}$ En este sentido, Carrasco Perera plantea que: “Aunque es cuestión discutida, y no hay pronunciamientos jurisprudenciales evidentes, en mi opinión la retroactividad se produce con efectos reales y la propiedad del bien entregado retorna al transmitente sin necesidad de nuevo acuerdo traslativo ni de entrega real o simbólica; lo que tiene importancia enorme, especialmente, a efectos concursales". CARRASCO PERERA, cit. (n. 15), pp. 1149-1150.

${ }^{66}$ Cfr. Dell'Aquila, cit. (n. 14), pp. 198-199.

${ }^{67}$ Cfr. Carrasco Perera, cit. (n. 15), p. 1153.

${ }^{68}$ Cfr. Fernández U; y Xiol Ríos, cit. (n. 31), pp. 1036-1037; Clemente Meoro, cit. (n. 3), pp. 13; Dell'Aquila, cit. (n. 14), pp. 198-199; Díez-Picazo y Ponce de León, cit. (n. 5), pp. 873 y ss.; Montés PenAdés, cit. (n. 43), p. 1165.

${ }^{69}$ Sobre este punto, Murillo González, Echeverría Summers y Erdozain López, en sus comentarios al $\mathrm{CC}$, señalan que: "El resarcimiento de daños y abono de intereses a que hace referencia el art. 1.124 $\mathrm{CC}$ es equivalente a la indemnización de daños y perjuicios del art. 1.101 del mismo texto legal, entendiéndose que el resarcimiento comprende tanto el damnum emergens, como el lucrum cesans (S.T.S. de 24 de septiembre de 1986 y 31 de mayo de 2002)". V. Murillo González, Echeverría Summers; Erdozain López, cit. (n. 36), p. 879.

${ }^{70}$ Cfr. Méndez y Vilalta, cit. (n. 37), p. 15.
} 
debe restituir la cosa principal, con sus accesorios y frutos. Nuevamente se esgrime como fundamento el principio de enriquecimiento sin causa. ${ }^{71}$

Con relación a los gastos necesarios en que ha incurrido uno de los contratantes, "[e]1 principio general que resulta de los arts. 453.1, 455, $472.1,1.518 .2^{\circ}$ y 1.898 C.C., es que los gastos necesarios han de abonarse al accipiens, pues son disminución de frutos. Si el solvens tiene derecho a que se le restituyan los frutos, el accipiens tiene derecho a que se le reembolsen los gastos necesarios para la conservación del bien y la obtención de los frutos, pues de otra manera el solvens se enriquecería injustamente a costa de aquél: recibiría los frutos y no tendría que pagar los gastos que habría tenido que hacer por sí mismo para obtenerlos". ${ }^{72}$

En general, la jurisprudencia ha reiterado que el fundamento de la repetición de la cosa dada o entregada en virtud de un contrato sujeto al derecho de opción, es la evitación de un enriquecimiento sin causa ${ }^{73}$ por parte de los contratantes. ${ }^{74}$ En efecto, la STS de 30 de diciembre de 2003 no sólo se apoya en el principio del enriquecimiento sin causa, sino que en la legislación vigente que existe sobre el tema (distintas acciones que suponen la devolución de los aportes al demandante vencedor), también significan la repetición de las aportaciones efectuadas por el demandado, conforme a los arts. 1124 y 1303 del CC, en las hipótesis en que no se aplican los arts. 1304 a 1306 del CC. ${ }^{75}$ Por otra parte, Albaladejo García señala que: "Si la resolución obliga a devolver cosa que fue mejorada, se aplican las reglas de resolución por incumplimiento de condición (arts. 1.123, $2^{\circ}, 1.122,6^{\circ}, y$ 487), no las de vencimiento en la posesión o liquidación del estado posesorio". ${ }^{76}$

\section{CONCLUSIONES}

Los requisitos del derecho de opción son dos: (a) la existencia de un

\footnotetext{
${ }^{71}$ Cfr. Clemente Meoro, cit. (n. 30), pp. 519-520.

${ }^{72}$ Cfr. Clemente Meoro, cit. (n. 30), pp. 526-527.

${ }^{73}$ En este sentido, Bercovitz Rodríguez-CANo señala que: "No es frecuente que la jurisprudencia relacione la restitución con la necesidad de evitar un enriquecimiento sin causa, lo que efectivamente tendría lugar a aquélla [...]”. BerCovitz Rodríguez-CANO, cit. (n. 28), p. 8251.

${ }^{74}$ En este sentido, la STS de 10 de junio de 2004 señala que la ruptura del vínculo obligatorio supone la necesidad de proceder a la repetición de las cosas que se hayan dado en virtud de dicha prestación. En igual sentido se pronuncian las STS de 15 de junio de 1992 y STS de 3 de junio de 1993. Cfr. FERNÁNDEZ U.; Xiol Ríos, cit. (n. 31), p. 1036.

${ }^{75}$ Ibídem, p. 1035.

${ }^{76}$ Albaladejo García, cit. (n. 26), p. 124.
} 
contratante negligente y (b) la presencia de un contratante diligente. El primero es aquel que reúne tres condiciones: (i) incumplimiento; (ii) imputabilidad y (iii) mora. Por su parte, el contratante diligente es aquel que cumplió su obligación, está dispuesto a cumplir, o no ha cumplido su obligación porque tiene a su favor una condición o un plazo.

No todo incumplimiento da lugar al derecho de opción: debe tratarse de un incumplimiento esencial. Ello excluye a los incumplimientos insignificantes. Esta esencialidad se determina sobre la base del principio de equidad natural y de la teoría de la frustración de los intereses de los contratantes.

A pesar de que la mayoría de los autores entienden que la imputabilidad no es un requisito del derecho de opción, pienso que ella debe ser considera por los jueces, toda vez que la conducta negligente de uno de los contratantes ha de ser sancionada por el Derecho. Cuando existe caso fortuito o fuerza mayor el deudor queda liberado de su obligación. En cambio, al existir dolo o culpa, el contratante diligente podrá ejercer las alternativas que le presenta su derecho de opción.

Es interesante el esfuerzo de la doctrina y la jurisprudencia para incluir a la resolución extrajudicial en el sistema jurídico español. Ello denota una apertura hacia la tendencia actual que impera en esta materia en Europa. El sistema alemán de la resolución extrajudicial permite no sólo descongestionar a los tribunales de justicia, sino que también permite que el acreedor logre satisfacer sus intereses de forma más eficiente y rápida. Con todo, es importante anotar que el tribunal siempre podrá determinar la legalidad de la resolución, verificando la existencia de sus requisitos, todo ello con el fin de evitar que la resolución extrajudicial se constituya como un mecanismo habitual sólo al servicio de intereses económicos.

Por último, estimo que al resolverse la obligación, el contrato (la causa eficiente de la obligación) subsiste y se transforma, ya que surge el deber del contratante incumplidor de realizar las prestaciones mutuas e indemnizar los daños y perjuicios.

\section{BIBLIOGRAFÍA}

Albaladejo García, Manuel, Derecho Civil. II. Derecho de Obligaciones, Edisofer, S. L., Madrid, 2011, 14ª edición, 1007 pp.

Badia Salillas, Ángel, "En torno al artículo 1.504 del Código Civil: Requerimiento, resolución y transmisión del derecho del vendedor", en AA.VV., Estudios jurídicos en homenaje a Tirso Carretero, Publicaciones del Cincuentenario del Ilustre Colegio Nacional de Registradores de la Propiedad y Mercantiles de España, Centro de Estudios Hipotecarios, Madrid, 1985, pp. 39-66. 
Bercovitz Rodríguez-Cano, Rodrigo (Director), Comentarios al Código Civil, Tirant lo Blanch, Valencia, 2013, T. VI, arts. 1043 a 1264, pp. 8249-8251.

Carrasco Perera, Ángel, Derecho de los contratos, Editorial Aranzadi, Navarra, 2010, 1286 pp.

Clemente Meoro, Mario E., "La resolución por incumplimiento en la propuesta para la modernización del derecho de obligaciones y contratos (2009) de la sección de derecho civil de la comisión general de codificación española", Boletín del Ministerio de Justicia, 2011 (mayo), año LXV, № 2131, disponible en http://www.mjusticia.es/ (consultado al 9 de marzo de 2014).

Clemente Meoro, Mario E., La facultad de resolver los contratos por incumplimiento, Tirant lo Blanch, Valencia, 1998, 703 pp.

De Cossio y Corral, Alfonso, Instituciones de Derecho civil, Editorial Civitas, S. A., Madrid, 1987, Tomo I, Parte General. Obligaciones y contratos, Revisado y puesto al día por Manuel de Cossio y Martínez, 496 pp.

Dell'Aquila, Enrico, La resolución del contrato bilateral por incumplimiento, Ediciones Universidad de Salamanca, Salamanca, 1981, Prólogo de José Luis de los Mozos, 213 pp.

Díez-Picazo y Ponce de León, Luis, Fundamentos del Derecho civil patrimonial, Editorial Aranzadi, Navarra, 2008, Vol. II, 'Las relaciones obligatorias', 6 Edición, 1092 pp.

Espiau Espiau, Santiago: La resolución unilateral del contrato: estudio jurisprudencial, Editorial Aranzadi, Pamplona, 1998. Aranzadi Civil-Mercantil, vol. I (Estudio), pp. 113-130; disponible en http://www.westlaw.es/, consultada el 3 de febrero de 2015.

Fernández Urzainqui, Francisco J.; Xiol Ríos, Juan A. (Directores), Código Civil, Grupo El Derecho y Quantor, S. L., Madrid, 2010.

Graves, Robert, Los mitos griegos (Trad. de Lucía Graves), Ariel, Barcelona, 1984, 249 pp.

Lacruz Berdejo, José L.; Sancho Rebullida, Francisco de A.; Luna Serrano, Agustín; Delgado Echeverría, Jesús; Rivero Hernández, Francisco; Rams Albesa, Joaquín, Elementos de Derecho Civil II. Derecho de Obligaciones, Dykinson, Madrid, 2007, Vol. 1º, Parte General. Teoría General del Contrato, $4^{\mathrm{a}}$ edición revisada y puesta al día por Francisco Rivero Hernández, 580 pp.

Lacruz Berdejo, José L.; Sancho Rebullida, Francisco de A.; Luna Serrano, Agustín; Delgado Echeverría, Jesús; Rivero Hernández, Francisco; Rams Albesa, Joaquín, Elementos de Derecho Civil II. Derecho de Obligaciones, Dykinson, Madrid, 2011, Vol. 1º, Parte General. Teoría General del Contrato, $5^{\mathrm{a}}$ Edición, revisada y puesta al día por Francisco Rivero Hernández, 608 pp.

Larenz, Karl, Derecho civil. Parte general, Editorial Revista de Derecho Privado, Madrid, 1978, 872 pp. 
Martorell Zulueta, Purificación (Coord.), Código Civil, Jurisprudencia sistematizada, Editorial Tirant lo Blanch, Valencia, 2011, 2094 pp.

Melich Orsini, José, La resolución del contrato por incumplimiento, Editorial Temis, Caracas, 1982, 433 pp.

Méndez Tomás, Rosa M.; Vilalta Nicuesa, A. Esther, La resolución contractual. Acción resolutoria en el contrato de compraventa, Ed. Bosch, Barcelona, 2002, $2^{\mathrm{a}}$ ed., $96 \mathrm{pp}$.

Miquel, Juan L., Resolución de los contratos por incumplimiento, Ediciones Depalma, Buenos Aires, 1986, 2ª Edición, actualizada, 381 pp.

Montés Penadés, Vicente L., “Artículo 1.124”, en Albaladejo G., Manuel (Director), Comentarios al Código Civil y Compilaciones Forales, Editorial Revista de Derecho Privado, Madrid, 1989, T. XV, Vol. 1, artículos 1.088 a 1.124 del Código Civil.

Murillo González, Fernando; Echeverría Summers, Francisco; Erdozain López, José C. (Coords.), Código Civil, concordado y comentado. Con jurisprudencia y doctrina de las audiencias provinciales. Ed. Tecnos (Grupo Anaya S.A.), Madrid, 2005.

Navarro Mendizábal, Iñigo A., Derecho de obligaciones y contratos, Ed. Aranzadi, S. A., Navarra, 2011, 725 pp.

O’Callaghan Muñoz, Xavier, Código Civil. Comentado y con jurisprudencia, Editorial La Ley-Actualidad, Madrid, 2001, 2 ${ }^{\mathrm{a}}$ Edición, 2251 pp.

O'Callaghan Muñoz, Xavier, Compendio de Derecho civil, Ediciones Jurídicas DIJUSA, S. L., Madrid, 2008, Tomo II, Derecho de obligaciones, Quinta edición, corregida y puesta al día, $749 \mathrm{pp}$.

Puig Brutau, José, Fundamentos de Derecho civil, Ed. Bosch, Barcelona, 1988, Tomo I, vol. II, $4^{a}$ edición revisada, Derecho General de las Obligaciones, $513 \mathrm{pp}$.

Puig i Ferriol, Lluís.; Gete-Alonso y Calera, María del C.; Gil Rodríguez, Jacinto; Hualde SÁnchez, José J., Manual de Derecho civil, Marcial Pons, Ediciones Jurídicas y Sociales, S. A., Barcelona, 2000, T. II, Derecho de obligaciones, responsabilidad civil y teoría general del contrato, $3^{\mathrm{a}}$ edición, $722 \mathrm{pp}$.

Rodríguez-RosAdo, Bruno, Resolución y sinalagma contractual, Marcial Pons, Ediciones Jurídicas y Sociales, Málaga, 2013.

Ruiz Serramalera, Ricardo, Derecho civil. Derecho de obligaciones II. Los contratos y los actos ilícitos, Universidad Complutense de Madrid, Facultad de Derecho, Secc. de Publicaciones, Madrid, 1982. 


\section{ÍNDICE DE SENTENCIAS}

\section{Jurisprudencia española}

- STS de 12 de septiembre de 2014 (RJ/2014/466).

- STS de 19 de febrero de 2014 (RJ/2014/92).

- STS de 20 de mayo de 2013 (RJ/2013/318).

- STS de 9 de mayo de 2013 (RJ/2013/241).

- STS de 29 de febrero de 2012 (RJ/2012/99).

- STS de 15 de noviembre de 2010 (RJ/2010/713).

- Auto del TS de 22 de junio de $2010 \mathrm{~N}^{\circ}$ Recurso 265/2009.

- STS de 14 de julio de 2008 (RJ/2008/707).

- STS de 9 de julio de 2008 (RJ/2008/652).

- STS de 17 de abril de 2006 (RJ/2006/411).

- STS de 23 de junio de 2005 (RJ/2005/503).

- STS de 28 de febrero de 2002 (RJ/2002/164).

- STS de 20 de diciembre de 2001 (RJ/2001/1196).

- STS de 12 de julio de 2001, No Recurso 1804/1996.

- STS de 31 de mayo de 1985 (RJ/1985/2837).

- STS de 5 de julio de 1980 (RA/1980/5846).

- STS de 20 de junio de 1980 (RJ/1980/2412).

- STS de 5 de mayo de 1980 (RJ/1980/1784).

- STS de 16 de octubre de 1967 (RJ/1967/3823).

- STS de 14 de marzo de 1964 (RJ/1964/1594).

- STS de 21 de noviembre de 1963 (RJ/1964/347).

- STS de 14 de noviembre de 1962 (RJ/1962/4289).

- STS de 10 de marzo de 1950 (RJ/1950/704).

\section{Jurisprudencia italiana}

- Sentencia de Casación de 6 de octubre de 1970 (n 1803$)$.

- Sentencia de Casación de 15 de marzo de $1972\left(\mathrm{n}^{\circ} 756\right)$.

- Sentencia de Casación de 13 de enero de 1972 ( $\left.\mathrm{n}^{\circ} 106\right)$.

- Sentencia de Casación de 23 de julio de 1964 (n 1986). 